\title{
Evaluation of Anterior Cruciate Ligament Partial Tear Injury Management
}

\author{
Asma Soud Badr ${ }^{1}$, Bodoor Salmi Almotairi², Abdulrahman Ahmed Alamir ${ }^{3}$, Abdulrahman \\ Mohammed Fahad Aldawsari ${ }^{4}$, Ammar Osama Alaaddin ${ }^{5}$, Ayman Khalil Alrushaydan ${ }^{6}$, Ahmed \\ Muteb Alanazi ${ }^{6}$, Abdalrashid Faisal Halawani ${ }^{7}$, Zead Ibrahim Alhussain ${ }^{8}$, Mansour Mana Al- \\ ghufaynah $^{9}$
}

1-King Faisal Hospital_ Makkah, 2- Taibah University, 3- Majmaah University,4- Prince Sattam Bin Abdulaziz University, 5- Umm Al-Quraa University, 6- Aljouf University, 7- King Abdulaziz University, 8- Arabian Gulf University,9- Alexandria University

\begin{abstract}
Background: Cruciate ligament is divided into two ligaments (Anterior Cruciate Ligament \& Posterior Cruciate Ligament) and is attached to the femur and tibia. The rate Anterior Cruciate Ligament partial tear is high among athletes and it is relatively high in comparison to other knee injuries. Anterior Cruciate Ligament partial tear commonly associated with hem-arthrosis of the knee and can evolve into complete tear. Various approaches have been suggested to treat Anterior Cruciate Ligament partial tear. However, deciding which approach to follow is still controversial. Objective: In this study we aimed at reviewing the current available literatures reporting on the management of partial tears of the ACL. Methods: PubMed database was used for articles selection, and the following keys used in the mesh ("Anterior Cruciate Ligament /partial tear"[Mesh] OR "Anterior Cruciate Ligament /management"[Mesh] OR "Anterior Cruciate Ligament /outcomes"[Mesh]). 10 studies were enrolled according to our inclusion, and exclusion criteria. Conclusion: The initial treatment after an ACL injury is rest, ice and usually crutches. Immobilization is important while the patient remains symptomatic. A course of conservative treatment by physiotherapy can be successful in patients not participating in strenuous physical activity. In patients with a high functional demand, even after a conservative program, surgical treatment is often required. Keeping ACL remnants when reconstructing the ACL is recommended. It might be beneficial on knee function because it preserves numerous mechanoreceptors that favor knee proprioception. In prepubescent children with several years of growth ahead, physicalsparing technique like Micheli technique is recommended. Less invasive techniques such as Thermal modification of knee's connective tissues can be suggested in order to reduce the dilemma and difficulty of the operation for the surgeon.
\end{abstract}

Key words: Anterior Cruciate Ligament, tear, athletes, knee injuries, physiotherapy, reconstruction.

\section{INTRODUCTION}

Cruciate ligament is divided into two ligaments (Anterior Cruciate Ligament \& Posterior Cruciate Ligament) and is attached to the femur and tibia. The tibia insertion is located anteriorly and close to the medial tibia eminence. The femoral attachment of the ACL is oval, on the posteromedial aspect of the lateral femoral condyle ${ }^{(1)}$. Both parts of cruciate ligament function as a knee stabilizer and allow gliding movements during leg bend and straighten process. ACL (ACL) as mentioned previously help in maintaining knee stability, also creates the connection between the femur and the tibia, and serves to prevent anterior translation of the tibia relative to the femur ${ }^{(2-3)}$.

ACL injury occurs mostly with athletes as a result of noncontact pivoting injury, typically a change of direction or deceleration maneuver ${ }^{(5)}$.
Patients often reports to feel a 'pop' and develop an immediate or sub-acute effusion. Often, athletes are not able to continue to play because of instability ${ }^{(1,3)}$.

ACL injuries are more frequently complete partial injuries have also been described. Partial injuries of the ACL are detected by magnetic resonance imaging and frequently present with a negative Lachman test ${ }^{(6-7)}$. Higher sensitivity is given by the pivot shift test. A definitive diagnosis of a single-bundle ACL lesion can be obtained by arthroscopy ${ }^{(9)}$.

In USA, the annual incidence is about 200,000, with at least 100,000 receiving arthroscopic reconstruction ${ }^{(10)}$. In KSA, a study done in Riyadh reported that the prevalence of ACL injury is about 31 per 100,000 individuals. Also, they reported that ACL injury is the most prevalent knee related injury (53\%), with young 
active participants being mostly affected (60\%). Another study indicated that incidence of anterior cruciate ligament injuries in general population ranges from 0.01 to $0.08 \%$ and the incidence is significantly higher among sports active population $(1.5-1.7 \%)^{(11-12)}$.

During the clinical practical life, surgical management of partial lesions of the ACL is relatively common. Recently, a lot of efforts have been done to improve the outcomes for the patients. In this paper our objective is to review the current available studies reporting on the management of partial tears of the ACL.

\section{METHODOLOGY}

\section{Sample}

PubMed database was used for articles selection, and the following keys used in the mesh ("Anterior Cruciate Ligament/partial tear"[Mesh] OR "Anterior Cruciate Ligament/management"[Mesh] OR "Anterior Cruciate Ligament/outcomes"[Mesh]). Inclusion criteria: The articles were selected based on the relevance to the project which should include one of the following topics, \{Anterior Cruciate Ligament, Management, Outcomes\}. Exclusion criteria were all other articles that did belong to one of these topics as their primary end point, or repeated studies.

\section{Analysis}

No software was used to analyze the data. The data were extracted based on specific form that contains (Title of the study, name of the author, Objective, Summary, Results, and Outcomes), these data were reviewed by the group members. Double revision of each member's outcomes was applied to ensure the validity of the results.

\section{RESULTS}

We enrolled 11 studies according to our inclusion, and exclusion criteria described above. All the studies aimed at evaluating different treatment modalities of partial ACL tear. The studies characteristics are shown in Table 1.

\section{DISCUSSION}

Knee pain may be one of the leading presentations to orthopedic clinics in the Kingdom of Saudi Arabia (KSA). In western societies, the ACL is the most frequently ruptured knee ligament. These injuries usually occur in younger patients, and have been shown to be a major risk factor for the development of future osteoarthritis. Nonetheless, osteoarthritic changes have been noted even after ACL reconstruction. The rate of partial tears ranges from $28 \%$ to $35 \%$ of distortional traumas of the knee with hem-arthrosis, and from $10 \%$ to $28 \%$ of all other ACL lesions ${ }^{(23)}$.

Barrack et al. ${ }^{(24)}$ in 1990 described the partial ACL tears and defined them according to clinical and arthroscopic criteria. It includes 3 parts. First, Lachman test must score zero or 1+ (less than $5 \mathrm{~mm}$ ). Lachman test is done by flexing the knee at 20-30 degrees with the patient supine. The examiner should place one hand behind the tibia and the other grasping the patient's thigh. The tibia is pulled forward to assess the amount of anterior motion of the tibia in comparison to the femur. An intact ACL should prevent forward translational movement. An instrument called a "KT-1000" can be used to determine the magnitude of movement in millimeters. The second element of (Barrack et al.) criteria is Pivot shift test. It should be negative or only trace-positive. This test is performed with the patient's knee starting in full extension. While maintaining internal rotation of the tibia, a valgus force is applied and the knee is slowly flexed to 25-30 degrees. In a normal knee, there will be no shift nor subluxation of the joint. If there is an ACL injury, the examiner will feel for a subluxation of the lateral tibial plateau as it reduces to its normal position. The third element is done by a diagnostic arthroscopy. When a significant portion of at least one bundle is healthy and is potentially functional as judged by palpation with a probe and arthroscopic anterior drawer testing (24).

Historically, ACL tears in patients with significant growth remaining were treated with activity modification and functional bracing until skeletal maturity, at which point conventional, trans-physeal ACL reconstruction was performed. Non-operative treatment may still have a role but has largely fallen out of favor because of re-injuries, often resulting in additional meniscal and articular cartilage damage. Non-operative treatment requires compliance with strict activity restrictions, the use of a functional knee brace, and frequent monitoring of compliance. By contrast, the results of early ACL reconstruction in skeletally immature patients have been generally favorable ${ }^{(25)}$. 
Table 1: The included studies.

\begin{tabular}{|c|c|c|c|c|c|c|}
\hline Study (year) & $\begin{array}{l}\text { Study } \\
\text { Design }\end{array}$ & Country & $\begin{array}{l}\text { Participants } \\
\text { (n) }\end{array}$ & Objective & $\begin{array}{l}\text { Duratio } \\
\mathrm{n}\end{array}$ & Outcome and Conclusion \\
\hline $\begin{array}{l}\text { Willimon et } \\
\text { al. }{ }^{(13)}\end{array}$ & $\begin{array}{l}\text { Case } \\
\text { series }\end{array}$ & USA & 21 & $\begin{array}{l}\text { To evaluate the clinical outcomes of a } \\
\text { physeal-sparing technique using the } \\
\text { iliotibial band for combined intra-articular } \\
\text { and extra-articular ACL reconstruction }\end{array}$ & 6 years & $\begin{array}{l}\text { Micheli procedure offers a safe and effective } \\
\text { ACL reconstruction option in children with } \\
\text { several years of growth remaining. Patients } \\
\text { returned to their preoperative activity level } \\
\text { after reconstruction. }\end{array}$ \\
\hline $\begin{array}{l}\text { Sonnery- } \\
\text { Cottet et al. } \\
\text { (14) }\end{array}$ & $\begin{array}{l}\text { Case } \\
\text { series }\end{array}$ & France & 36 & $\begin{array}{l}\text { To describe an original technique of } \\
\text { reconstruction of the anteromedial bundle } \\
\text { preserving the posterolateral bundle }\end{array}$ & 2 years & $\begin{array}{l}\text { Selective AM bundle reconstruction is } \\
\text { recommended because it demonstrates a low } \\
\text { side to side laxity. The functional value of } \\
\text { the preserved fibers has to be further } \\
\text { evaluated from a mechanical and biological } \\
\text { point of view. }\end{array}$ \\
\hline Buda et al. ${ }^{(15)}$ & $\begin{array}{l}\text { Case } \\
\text { series }\end{array}$ & Italy & 47 & $\begin{array}{l}\text { To perform a prospective analysis of the } \\
\text { results of augmentation surgery using } \\
\text { gracilis and semitendinosus tendons to treat } \\
\text { partial sub-acute lesions of the ACL }\end{array}$ & 5 years & $\begin{array}{l}\text { Augmentation surgery using gracilis and } \\
\text { semitendinosus tendons is compatible with } \\
\text { the ACL anatomy and provides good results } \\
\text { thanks to the maintenance of the intact } \\
\text { bundle, with its mechanical support and } \\
\text { vessel and nerve supply. }\end{array}$ \\
\hline Buda et al. ${ }^{(16)}$ & $\begin{array}{l}\text { Case } \\
\text { series }\end{array}$ & Italy & 28 & $\begin{array}{l}\text { To evaluate the mid-term MRI appearance } \\
\text { of partial ACL tear augmentation with } \\
\text { quadrupled distally inserted hamstrings, } \\
\text { while preserving the intact ACL bundle }\end{array}$ & 2 years & $\begin{array}{l}\text { MRI scanning is useful in evaluating } \\
\text { hamstring ACL grafts after reconstruction }\end{array}$ \\
\hline Ochi et al. ${ }^{(17)}$ & $\begin{array}{l}\text { Case } \\
\text { series }\end{array}$ & Japan & 45 & $\begin{array}{l}\text { To investigate clinical results of } \mathrm{ACL} \\
\text { augmentation procedure using an } \\
\text { autogenous semitendinosus tendon }\end{array}$ & 9 years & $\begin{array}{l}\text { Selective AM or PL bundle reconstruction } \\
\text { showed improved joint stability, joint } \\
\text { position sense, and Lysholm scores } \\
\text { postoperatively. This procedure can be a } \\
\text { treatment option for patients whose ACL } \\
\text { remnants are left in certain conditions. }\end{array}$ \\
\hline $\begin{array}{l}\text { Serrano- } \\
\text { Fernandez et } \\
\text { al. }{ }^{(18)}\end{array}$ & $\begin{array}{l}\text { Case } \\
\text { series }\end{array}$ & Spain & 24 & $\begin{array}{l}\text { To present a surgical augmentation } \\
\text { technique for partial ACL ruptures in which } \\
\text { an isolated, autologous, double-bundle } \\
\text { semitendinosus tendon graft is passed over } \\
\text { the top of the femur, thus fully preserving } \\
\text { the still-intact fibers of the ligament } \\
\text { remnant }\end{array}$ & 14 & $\begin{array}{l}\text { The described procedure is compatible with } \\
\text { ACL anatomy } \\
\text { and achieves good results by maintaining } \\
\text { the intact bundle }\end{array}$ \\
\hline Buda et al. ${ }^{(19)}$ & $\begin{array}{l}\text { Case } \\
\text { series }\end{array}$ & Italy & 52 & $\begin{array}{l}\text { To compare the outcome of anatomic } \\
\text { reconstruction of the torn bundle with non- } \\
\text { anatomic augmentation using the over-the- } \\
\text { top femoral route }\end{array}$ & & $\begin{array}{l}\text { The non-anatomic augmentation technique } \\
\text { is simpler than the anatomic reconstruction } \\
\text { technique, providing excellent durable } \\
\text { results over time with a lower complication } \\
\text { rate }\end{array}$ \\
\hline $\begin{array}{ll}\text { Demirăg } & e t \\
a l . & \end{array}$ & $\begin{array}{l}\text { Case } \\
\text { series }\end{array}$ & Turkey & 40 & $\begin{array}{l}\text { To compare the clinical outcome and } \\
\text { possible complications of augmentation } \\
\text { technique and standard reconstruction for } \\
\text { the treatment of partial ACL tears }\end{array}$ & 3 years & $\begin{array}{l}\text { In the repair of partial ACL tears, } \\
\text { augmentation technique is as effective as the } \\
\text { standard technique, leading to, less tunnel } \\
\text { widening evidently in the tibial tunnel, } \\
\text { particularly. }\end{array}$ \\
\hline Yoon et al. ${ }^{(21)}$ & $\begin{array}{l}\text { retrospe } \\
\text { ctive } \\
\text { compara } \\
\text { tive } \\
\text { study }\end{array}$ & $\begin{array}{l}\text { South } \\
\text { Korea }\end{array}$ & 164 & $\begin{array}{l}\text { To analyze differences in injury } \\
\text { mechanism, preoperative physical } \\
\text { examination findings, combined injury } \\
\text { pattern, and postoperative clinical results } \\
\text { among arthroscopic ACL reconstruction, } \\
\text { anteromedial (AM) augmentation, and } \\
\text { posterolateral (PL) augmentation with } \\
\text { hamstring autograft }\end{array}$ & 2 years & $\begin{array}{l}\text { The AM augmentation group was injured } \\
\text { more by a direct injury mechanism, and it } \\
\text { presented with a greater incidence of medial } \\
\text { collateral ligament tear than the PL } \\
\text { augmentation group. MRI was useful for } \\
\text { detection } \\
\text { of remnant ACL fibers. }\end{array}$ \\
\hline$\underset{(22)}{\operatorname{Lamar}}$ et al. & $\begin{array}{l}\text { Case } \\
\text { series }\end{array}$ & USA & 13 & $\begin{array}{l}\text { To evaluate the effectiveness of thermal } \\
\text { modification for the treatment of partial } \\
\text { tears of the ACL }\end{array}$ & 2 years & $\begin{array}{l}\text { With cautious application, thermal } \\
\text { modification may be a viable treatment } \\
\text { option for partial tears of the ACL in a select } \\
\text { subset of patients. }\end{array}$ \\
\hline
\end{tabular}


Regardless of age and activity level, the initial treatment after an ACL injury is rest, ice and usually crutches. Immobilization is important while the patient remains symptomatic. For individuals who choose not to have surgery, rehabilitation of the injured knee is frequently recommended to restore as much function as possible and help prevent instability. Rehabilitation focuses on strengthening the muscles around the knee in order to provide better support, control and stability. Some athletes may choose a non-surgical approach to finish a sports season and have reconstructive surgery later. Initially, conservative treatment by physiotherapy is aimed at reducing swelling, restoring the range of movement at the knee and restoring full muscle power. It can also help to improve confidence in walking and regaining trust in knee function. Once the knee is more settled, a large part of physiotherapy management is aimed at addressing any muscle weakness present around the knee, hip, spine and pelvis and any deficits in proprioception. Proprioception can be re-trained using exercises designed to test your balance and coordination. Stability of the knee can be improved with intensive physiotherapy exercises, not just for strengthening the muscles at the front (quadriceps) and the back (hamstrings) of the knee but more importantly for improving balance, proprioception and endurance. Sometimes knee braces are used to facilitate physiotherapy. Bracing is another way of stabilizing the knee without surgery and there are purpose made ACL braces which protect the joint and can be very valuable during certain sports. Good muscle performance and enhanced proprioception are both key factors in a successful conservative management approach to ACL injury. Adjustments may be required to daily activities and sports whilst having physiotherapy ${ }^{(26)}$.

Conservative treatment of partial ACL tears can be successful in patients not participating in strenuous physical activity. This is not recommended for most sports but can be successful in single plane sports that require minimal pivoting or side to side movements like sprinting athletes and designated hitters in baseball and softball. In patients with a high functional demand, even after a conservative program, surgical treatment is often required, because of the persistence of symptomatic instability. When ACL reconstruction is required, a standard procedure is generally used, thus sacrificing the residual portion of the ACL. Traditional ACL reconstruction techniques recommended the resection of the remaining ligament tissue to avoid overstuffing the intercondylar notch and prevent impingement of tissues that can lead to decreased range of motion of the operated knee. That being said, the resection of ACL fibers that remain in continuity may be counterproductive for the knee as these fibers have the capacity to produce collagen and contain numerous mechanoreceptors that favor knee proprioception. Therefore, keeping ACL remnants when reconstructing the ACL (anatomic reconstruction) may prove to be beneficial on knee function, especially if these remnants correspond to one of the native ACL bundles. Many studies found that combination of AM bundle reconstruction with an outside-in technique remains simple and reproducible. The outside-in technique is femoral tunnel creation by using outside-in retrograde drilling. The results of their studies are encouraging with excellent side to side laxity. This combination technique showed improved joint stability, and joint position sense ${ }^{(17)}$. However, a singlebundle ACL tear is difficult to diagnose. The diagnosis is made during arthroscopy and selective reconstruction can be proposed. This outside-in surgical technique enables reconstruction of the ruptured ligament while preserving the intact native fibers. ${ }^{(14)}$ Anatomic reconstruction of the torn bundle is technically challenging, requiring adapted portals, perfect control of the instruments during tunnel reaming, and intercondylar space management, which is crucial, especially when dealing with small knees. Augmentation of the torn bundle using the over-the-top femoral passage, avoiding femoral tunnel reaming, may represent a solution able to overcome the majority of technical difficulties encompassed by anatomic techniques ${ }^{(19)}$. Buda et al. $^{(20)}$ in 2013 conducted a comparative study between anatomic and non-anatomic reconstruction of partial ACL tear using the over-the-top femoral route regarding long-term postoperative outcome. They found the non-anatomic augmentation technique is simpler than the anatomic reconstruction technique, providing excellent durable results over time with a lower complication rate. Anteromedial bundle reconstruction is associated with a poorer outcome, especially when performed with anatomic reconstruction ${ }^{(19)}$.In prepubescent 
children with several years of growth ahead, Micheli technique is recommended by Willimon et al. ${ }^{(13)}$. This is a physeal-sparing technique which uses the iliotibial band for combined intra-articular and extra-articular ACL reconstruction. Willimon et al. ${ }^{(13)}$ group found that Micheli technique offers a safe and effective alternative to trans-physeal reconstruction. However, The use of isolated iliotibial band tenodesis did not fare well in adults. Failure and revision rates among adults are higher than the rates among young patients (13).

Less invasive techniques can be suggested in order to reduce the dilemma and difficulty of the operation for the surgeon. The emergence of basic science and clinical data involving new minimally invasive thermal techniques in other areas has enticed some surgeons to expand their application to the treatment of partial ACL tears. Thermal modification of connective tissues has been applied to a variety of tissues. However, significant questions remain concerning its long-term efficacy and ability to maintain adequate soft-tissue tension. This technique uses thermal energy to restructure collagen in the capsule or ligaments to reduce the capsule size. It also involve the application of heat using a specialized radiofrequency probe to shrink and tighten tissues. Tendons and ligaments are primarily composed of collagen, a type of protein. When collagen is heated to the appropriate temperature, it contracts and shrinks. The body perceives this as an injury and the tissues rebuild around shorter collagen fibers, resulting in a tighter and theoretically improved joint stability. Lamar et al. ${ }^{(22)}$ showed a possible application in the treatment of acute partial (less than 50\%) tears of a native ACL in patients who are not high-demand, high-performance athletes but who complain of instability.

\section{CONCLUSION}

Regardless of age and activity level, the initial treatment after an ACL injury is rest, ice and usually crutches. Immobilization is important while the patient remains symptomatic. A course of conservative treatment by physiotherapy can be successful in patients not participating in strenuous physical activity. In patients with a high functional demand, even after a conservative program, surgical treatment is often required. When ACL reconstruction is required in the repair of partial ACL tears, keeping ACL remnants when reconstructing the
ACL (anatomic reconstruction) is recommended. It might be beneficial on knee function because it preserves numerous mechanoreceptors that favor knee proprioception. In prepubescent children with several years of growth ahead, physeal-sparing technique like Micheli technique is recommended. Less invasive techniques such as Thermal modification of knee's connective tissues can be suggested in order to reduce the dilemma and difficulty of the operation for the surgeon.

\section{REFERENCES}

1. Adachi N, Ochi M, Uchio Y et al. (2002): Mechanoreceptors in the anterior cruciate ligament contribute to the joint position sense. Acta Orthop Scand., 73:330-33.

2. Alghamdi S, Alghamdi M, Alghamdi A et al. (2017): Awareness about Cruciate Ligament Injury among General Population of Albaha City. The Egyptian Journal of Hospital Medicine, 69(1):1614-1623.

3. Rumian AP, Wallace AL and Birch HL (2007): Tendons and ligaments are anatomically distinct but overlap in molecular and morphological features - a comparative study in an ovine model. Journal of Orthopaedic Research, 25: 458-464.

4. Kumar K and Maffulli N (1999): The ligament augmentation device:an historical perspective. Arthroscopy, 15:422-432.

5. Warner SJ, Smith MV, Wright RW et al. (2011): Sport-specific outcomes after anterior cruciate ligament reconstruction. Arthroscopy, 27:11291134.

6. Ramjug S, Ghosh S, Walley G et al. (2008): Isolated anterior cruciate ligament deficiency, knee scores and function. Acta Orthop Belg., 74:643651.

7. Crawford R, Walley G, Bridgman $\mathbf{S}$ et al. (2007): Magnetic resonance imaging versus arthroscopy in the diagnosis of knee pathology, concentrating on meniscal lesions and ACL tears: a systematic review. $\mathrm{Br}$ Med Bull., 84:5-23.

8. Colombet P, Dejour D, Panisset JC et al. (2010): Current concept of partial 
anterior cruciate ligament ruptures. Orthop Traumatol Surg Res., 96:S109S118.

9. Georgoulis AD, Pappa L, Moebius U et al. (2001): The presence of proprioceptive mechanoreceptors in the remnants of the ruptured ACL as a possible source of re-innervation of the ACL autograft. KneeSurg Sports Traumatol Arthrosc., 9:364-368.

10. Griffin LY, Agel J, Albohm MJ et al. (2000): Noncontact anterior cruciate ligament injuries: risk factors and prevention strategies. J Am Acad Orthop Surg., 8:141-150.

11. Beynnon BD, Ettlinger $\mathrm{CF}$ and Johnson RJ (2011): Epidemiology and mechanisms of ACL injury in alpine skiing. American Orthopaedic Society for Sports Medicine, 39(7):183-188.

12. Salmon $L$, Russell V, Musgrove $T$ et al. (2005): Incidence and risk factors for graft rupture and contralateral rupture after anterior cruciate ligament reconstruction. Arthroscopy, 21(8): 948-57.

13. Willimon $\mathrm{S}$, Christopher R, Mackenzie M et al. (2015): Anterior Cruciate Ligament Reconstruction in Skeletally Immature Youths. The American Journal of Sports Medicine, 43(12): 2974-981.

14. Bertrand $S$, Lavoie $R$, Ogassawara $R$ et al. (2015): Selective Anteromedial Bundle Reconstruction in Partial ACL Tears: A Series of 36 Patients with Mean 24 months Follow-up. Rev Bras Ortop., 50(1): 9-15.

15. Buda R, Alberto F, Francesca $V$ et al. (2015): Augmentation Technique with Semitendinosus and Gracilis Tendons in Chronic Partial Lesions of the ACL: Clinical and Arthrometric Analysis. Knee Surgery, Sports Traumatology, Arthroscopy, 14(11): 1101-1107.

16. Buda R, Caprio F, Giuriati L et al. (2008): Partial ACL Tears Augmented with Distally Inserted Hamstring Tendons and Over-the-top Fixation: An MRI Evaluation. The Knee, 15(2): 111-116.

17. Ochi M, Nobuo A, Yuji U et al. (2009): A Minimum 2-Year Follow-up After Selective Anteromedial or
Posterolateral Bundle Anterior Cruciate Ligament Reconstruction. Arthroscopy: The Journal of Arthroscopic \& Related Surgery, 25(2): 117-122.

18. Serrano-Fernandez, Jose M, Alejandro E et al. (2010): Augmentation Technique for Partial ACL Ruptures Using Semitendinosus Tendon in the Over-the-top Position. Knee Surgery, Sports Traumatology, Arthroscopy, 18(9): 1214-1218.

19. Buda $R$, Alberto $R$, Alessandro $P$ et al. (2013): Partial ACL Tears: Anatomic Reconstruction Versus Nonanatomic Augmentation Surgery. Orthopedis, 36(9):1108-1113.

20. Demiră B, Ermutlu C, Aydemir F et al. (2012): A comparison of clinical outcome of augmentation and standard reconstruction techniques for partial anterior cruciate ligament tears. Eklem Hastalik Cerrahisi., 23:140-4.

21. Yoon $K$, Dae $K$, Seung $M$ et al. (2009): Standard Anterior Cruciate Ligament Reconstruction Versus Isolated Single-Bundle Augmentation with Hamstring Autograft. Arthroscopy: The Journal of Arthroscopic \& Related Surgery, 25(11): 1265-1274.

22. Lamar D, Bartolozzi A, Freedman $K$ et al. (2005): Thermal Modification of Partial Tears of the Anterior Cruciate Ligament. Arthroscopy: The Journal of Arthroscopic \& Related Surgery, 21(7): 809-814.

23. Abbas M, Abulaban A and Darwish H (2013): Functional outcomes of bone tendon bone versus soft tissue arthroscopic anterior cruciate ligament reconstruction: a comparative study. Saudi medical journal, 34(2): 153-160.

24. Barrack RI, Buckley Sl, Bruckner Jd et al. (1990): Partial versus Complete Acute Anterior Cruciate Ligament Tears. The Results of Nonoperative Treatment." The Journal of Bone and Joint Surgery,72(4): 622-624.

25. Beard D, and Dodd C (1998): Home or Supervised Rehabilitation Following Anterior cruciate Ligament Reconstruction: A Randomized Controlled Trial. Journal of 
Asma Badr et al.

Orthopaedic \& Sports Physical Therapy, 27:134-143.

26. Nisonson B (1991): Anterior Cruciate Ligament Injuries. Conservative Vs.
Surgical Treatment. Journal of Pediatric Orthopaedics, 11(6):815-823. 